\title{
A TEORIA COMPLEXA E SUAS IMPLICAÇÓES PARA UMA PROPOSTA DE EDUCAÇÃO INTEGRAL
}

\author{
Jamile Cabreira ${ }^{1}$ \\ Mariane Moser Bach ${ }^{2}$
}

\begin{abstract}
Resumo: Neste artigo discutimos implicaçôes que a proposta de educação integral traz para a promoçáo e emancipação humana/social do sujeito e de sua aprendizagem escolar. Mediante uma metodologia qualitativa e exploratória, são explicitados entendimentos acerca do conceito de educação integral e suas contribuiçóes para uma prática interdisciplinar que possibilite a ligaçáo dos saberes e das experiências de mundo vivenciadas pelos sujeitos. Os resultados colocam em destaque a educação integral como possibilidade para a promoção do sujeito em sua integralidade, e a necessidade de uma reforma educacional que contribua para um projeto societário emancipador do sujeito em questão. Nas conclusóes é reafirmada a importância da educação integral no currículo escolar, como uma alternativa de nova proposta de educaçáo na contemporaneidade, como uma possibilidade de reforma de pensamento em prol do desenvolvimento humano/social emancipatório.
\end{abstract}

Palavras-chave: Escola; Educação integral; Complexidade.

\section{COMPLEX THEORY AND ITS IMPLICATIONS FOR A INTEGRAL EDUCATION PROPOSAL}

\begin{abstract}
In this article we discuss the implications that the proposal of integral education brings for the promotion and human/social emancipation of the subject and his/her school learning. Through a qualitative and exploratory methodology, understandings about the concept of integral education and its contributions to an interdisciplinary practice that enable the connection of knowledge and world experiences experienced by the subjects are explained. The results highlight integral education as a possibility to promote the subject in its entirety and the need for an educational reform that contributes to a societal project that emancipates the subject in question. The conclusions reaffirm the importance of integral education in the school curriculum as an alternative to a new proposal for
\end{abstract}

1 Mestra em Educação nas Ciências pela Unijuí; especialista em Pedagogia Social pela Uníntese; graduada em Pedagogia pela Unijuí; professora da Rede Municipal de Ensino de Ijuí/RS. Contato: jamilecabreira1107@gmail.com

2 Mestra em Educação nas Ciências pela Unijuí; graduada em Letras - Português e Inglês pela Unijuí, professora da rede pública e privada de Ijuí/RS. Contato: mariane.bach@gmail.com 
contemporary education, as a possibility of thought reform in favor of emancipatory human/social development.

Keywords: School; Integral education; Complexity.

\section{Introduçáo}

Espera-se que a educaçáo prepare os sujeitos para enfrentar as diversidades presentes na sociedade de forma independente e reflexiva, exercendo de fato o direito à cidadania. Há muitas instituiçôes sociais responsáveis por educar um sujeito, entretanto uma delas destaca-se nessa ação. Referimo-nos à escola, que, a partir do projeto iluminista de universalizaçáo da educação, foi, gradativamente, estendendo sua ação sobre a sociedade, tornando-se a instituição responsável pela transmissão, veiculação e socialização do conhecimento. Para muitos, ela é a única oportunidade de compartilhar vivências significativas e construir conhecimento.

Diante de tamanha responsabilidade, a instituição escolar passa por profundas transformaçóes coerentes com as exigências da sociedade contemporânea. Tais exigências, demandadas pela cultura globalizada, pelas novas tecnologias e pela sociedade de consumo, impóem, de fato, mudanças na organização da escola; mudanças essas que não se restringem ao seu jeito de ensinar (métodos e situações de aprendizagens), mas estendem-se também a seus espaços, ao seu tempo e ao seu currículo, para que a proposta educacional possa ser ressignificada e pensada de acordo com as novas exigências da contemporaneidade. Não há mais como pensar a educação de forma fragmentada e descontextualizada do mundo real.

A teoria da complexidade de Edgar Morin (2008, 2006, 2004, 2003) nos proporciona uma visão ampla e aberta do todo, permitindo romper com a fragmentaçáo do conhecimento e das disciplinas do currículo e suas formas de ensino compartimentalizadas e desconexas da realidade. Pensando em instituir um novo paradigma para a educaçáo é que se propóe algumas discussóes no presente artigo, acerca da proposta de educação integral como possibilidade de romper com a fragmentação curricular, que separa os saberes escolares em disciplinas isoladas e compartimentalizadas e que tem se mostrado ineficiente para a aprendizagem. Este modelo de educação tem sido reproduzido como padrão nas práticas escolares da educação pública de nosso país.

Sendo assim, num primeiro momento, são trazidas contribuições sob a ótica de autores como Gadotti, (2009) Guará, (2006), Moll (2008), sobre os desafios que a proposta de uma educação integral traz para a instituição escolar. Em seguida, a partir da teoria da complexidade de Edgar Morin (2008, 2006, 2004, 2003), reflete-se acerca dos entraves que a divisão disciplinar traz para o desenvolvimento integral do sujeito, na medida em que separa o conjunto de elementos específicos do humano (físicos, sociais, cognitivos, culturais etc.), o qual necessita ser considerado para o seu desenvolvimento no decorrer do processo de aprendizagem. Assim, emerge a necessidade de uma reforma educacional que pense a educaçáo na sua integralidade, que possa contribuir para um projeto societário emancipador do sujeito em questão. 
Cabe destacar, que o instrumento metodológico escolhido para a seleção das fontes de pesquisa foi a revisão bibliográfica narrativa. Em consonância com Rother (2007), esse tipo de revisão é apropriado para descrever e discutir o desenvolvimento de um assunto, sob ponto de vista teórico ou contextual, sendo a literatura selecionada a partir da interpretaçáo e análise crítica e pessoal dos autores. Dessa maneira, as obras aqui escolhidas para compor a fundamentação teórica foram selecionadas a partir da sua aproximaçáo com o tema de pesquisa, no objetivo de contribuirmos para a atualização desse debate.

\section{Educaçáo Integral e seus desafios para a instituiçáo escolar}

Com a universalização do ensino estendido a todos os cidadáos, a sociedade passa a lutar por mais escolas e por qualidade de ensino nelas. Nesse debate estáo envolvidos estudiosos da educação, a sociedade e o Estado, que por mais que tenham interesses distintos em meio a essa luta, têm em comum a ideia de reformas que sejam capazes de trazer melhorias para a Educação do país.

O projeto de Educação Integral no Brasil, tem suas origens nas ideias de Anísio Teixeira, que já no século passado evidencia a importância de uma educação integral e em tempo integral, para o desenvolvimento pleno do sujeito. Dando continuidade aos ideais de Teixeira, Darcy Ribeiro idealiza um projeto de escola pública que incorpora tais princípios. Assim nascem os Centros Integrados de Educação Pública (CIEPs).

Muitas foram as discussões travadas ao longo desse período, além de experiências voltadas para a implantaçáo de uma proposta que contemplasse a educação integral. No entanto, as idas e vindas desse conjunto de ideias, vinculadas a projetos políticos e sociais, não surtiram o efeito esperado, trazendo questionamentos acerca desse tema até os dias de hoje. Essa temática, novamente, vem ganhando força no cenário da educação pública brasileira, que busca encontrar estratégias que garantam uma educaçáo integral sólida e eficiente nas escolas de turno integral ou parcial.

Embora as legislações (Constituição Federal, Lei de Diretrizes e Bases da Educação Nacional, Estatuto da Criança e do Adolescente) já ressaltem o compromisso do Estado e da sociedade com a educaçáo integral do sujeito, ainda há dúvidas de como desenvolvê-la de fato nos currículos das escolas, cumprindo com o objetivo da formação na sua integralidade. Segundo Guará (2006, p. 15):

Isoladamente, nenhuma norma legal, concepção ou área da política social dá conta do atendimento completo pretendido pelas propostas de educação integral. A perspectiva que adotamos é, portanto, a da necessidade de uma composição de estratégias e alternativas políticas e pedagógicas para repensarmos o modo de funcionamento das instituiçóes educativas, a fim de colocá-las a favor da lógica da inclusão e da formação integral das crianças e adolescentes.

Pensar o modo de funcionamento das instituiçóes escolares, tendo em vista um projeto integral de educação, sem dúvida remete à necessidade de se reformar $\mathrm{o}$ 
pensamento educacional e o currículo das instituiçóes escolares. Essa reforma deve, assim, abandonar as práticas que fragmentam o conhecimento apresentado em forma de disciplinas, a descontextualização do estudo dos objetos, a separação dos problemas reais e cotidianos dos saberes científicos. É uma reforma que pretende estimular aptidóes nos sujeitos, de modo a encorajá-los a um pensar racional e autônomo acerca do todo que compóe o universo em que estes encontram-se inseridos.

Disso decorre que, para a educação do futuro, é necessário promover grande remembramento dos conhecimentos oriundos das ciências naturais, a fim de situar a condição humana no mundo, dos conhecimentos derivados das ciências humanas para colocar em evidência a multidimensionalidade e a complexidade humanas, bem como integrar (na educação do futuro) a contribuição inestimável das humanidades, não somente a filosofia e a história, mas também a literatura, a poesia, as artes (MORIN, 2006, p. 48).

A importância de uma contextualização das disciplinas que compóe o currículo escolar corrobora para a construção de uma nova proposta educacional, que pensa o aluno em sua integralidade e que contribui para que este entenda as ligações que foram sendo construídas ao longo do processo de ensino-aprendizagem, para se chegar ao conhecimento sem fragmentá-lo. Esse é um dos grandes desafios do ensino, pois as práticas que se desenvolvem no contexto escolar, na maioria das vezes, são decorrentes de uma visão positivista e tecnicista que busca o conhecimento sem interligar os saberes.

Assim sendo, a ideia de educar integralmente lembra a importância de se pensar em situaçóes de aprendizagens que estimulem o desenvolvimento de diferentes habilidades do sujeito, possibilitando a este uma formação que lhe constitua um ser social em sua plenitude. Da escola espera-se que apresente um projeto político-pedagógico que agregue ações indispensáveis ao desenvolvimento integral do ser humano. Que possa propor uma reforma educacional que pense na ligaçáo plena dos conhecimentos e saberes veiculados na escola.

Entretanto, essa ação não acontece de forma neutra, ela esbarra no tempo, no espaço e no esforço de professores e demais profissionais da educação, para reformar o pensamento em relação a um fazer pedagógico que priorize o ensino integral. Em meio a esta urgência de se pensar um novo projeto para a educação, percebe-se que a mesma tem encontrado adversidades para concretizar as açóes que se pretendem inovadoras, uma vez que há resistência em se reinventar diante de complexas e desafiadoras questôes sociais, políticas e econômicas que se apresentam para a escola. Essas questôes têm deixado as relaçóes tensas e complexas dentro da instituição escolar e das demais instituiçóes envolvidas nesse processo - família, Estado, sociedade como um todo - dificultando ainda mais a implantaçáo de um projeto de educaçáo que se pretende avançar em qualidade e na formaçáo dos sujeitos que educa. De acordo com Moll:

[...] à compreensão de que os processos educativos na contemporaneidade transcendem a instituição escolar - passam impreterivelmente pela escola - mas articulam-se, ou devem articular-se, a uma ampla rede de políticas 
sociais e culturais, de atores sociais e de equipamentos públicos. Portanto, Educaçáo Integral pressupóe escola pública, de qualidade e para tod@s em articulação com espaços/políticas/atores que possibilitem a construção de novos territórios físicos e simbólicos de educação pública. Desconsiderandose tal perspectiva, corre-se o risco de pensar na escola como instituição total, na política de Educaçáo Integral como a nova panacéia para resolução dos clássicos problemas da educação pública e nas práticas de "hiper-escolarização" como resposta ao não aprender (MOLL, 2008, p.12).

Entender a educação integral como um processo amplo e dinâmico éo primeiro passo para reconhecermos a sua complexidade e evitar centralizar a responsabilidade apenas em uma única instituição: a escola. Educar é uma ação que exige esforço de um coletivo de instituiçóes, que juntas ganham força para criar estratégias de aprendizagens, que em conjunto com a escola possibilitam experiências educativas que são significativas e reais para o sujeito imerso nesse projeto.

No caso específico da escola, é necessário que o grupo docente tenha clareza da proposta de educação integral, para que possa traçar estratégias que trabalhem a construção do conhecimento científico de modo interligado e contextualizado com a realidade a qual pertencem. Desse modo, é importante o engajamento dos professores nesse processo, para que o planejamento seja realizado de modo interdisciplinar, contemplando assim o desenvolvimento das necessidades integrais dos alunos.

A avaliação deve caminhar junto ao processo de ensino-aprendizagem para que se tenha a oportunidade de refletir sobre a prática diária e, dessa forma, problematizar a açáo desenvolvida. Todo o projeto que tenha por intenção ensinar sujeitos deve ser planejado e avaliado constantemente pelo grupo de profissionais que o executam, com a participação de uma gestão democrática, que sempre estará aberta para dialogar e refletir sobre as açóes que devem ser tomadas em benefício da aprendizagem e do desenvolvimento dos seres humanos que educa.

Conduzir o aluno para que construa o conhecimento útil para seu dia a dia é um desafio vivido pelos professores em meio a um desenho curricular fragmentado pelas disciplinas. As políticas educacionais que mudam ou são repaginadas a cada troca de governo, também se constituem como um entrave para a implantação de um projeto de educação que se responsabilize e invista em um trabalho que, verdadeiramente, ocupe-se em construir saberes e aprendizagens para o avanço da educação. Além disso, a cobrança por índices satisfatórios de aprendizagem tensiona as relaçôes na escola e compromete o trabalho pedagógico, pois a avaliação tornase o objeto final para "medir" níveis de aprendizagens, sem considerar o processo como um todo e suas relaçôes com as diferentes áreas do conhecimento.

É pensando nessa direção que a proposta de educação integral vem desafiar a ação pedagógica do professor e até mesmo compartilhar desse compromisso com as demais instituiçôes responsáveis por tal educação.

O debate da Educação Integral ganha sentido, portanto, nas possibilidades, que estão sendo e que serão construídas, de reinvenção da prática educativa escolar no sentido de seu desenclausuramento, de seu reencontro com a vida, 
do desenrijecimento de seus tempos, da interlocução entre os campos do conhecimento em função da compreensão e da inserção qualificada no mundo. No reencontro com a vida coloca-se a perspectiva de um projeto educativo que, ancorado na instituição escolar, possa recriar seu sentido na relação com outros interlocutores, outros espaços, outras políticas e equipamentos públicos (MOLL, 2008, p.13).

Compreender a educação integral como uma proposta educacional que considera o sujeito na sua plenitude, acreditando que ele é capaz de aprender ao longo de sua vida e em diferentes espaços, faz-se necessário para ressignificar as práticas pedagógicas da escola que ainda fragmentam o conhecimento como sendo algo isolado, único e que ocorre em dado momento e em dada situação. Educar integralmente é estimular o sujeito a desenvolver-se enquanto homem pensante, ativo e produtivo, capaz de se reinventar e de se adaptar às mais distintas situaçóes da sociedade a qual está inserido. Sendo assim, um ensino que promove uma formação tecnicista e fragmentada, não condiz com o objetivo de uma educação que pretende ser integral. $\mathrm{O}$ desenvolvimento do ser humano ultrapassa a aquisição de conceitos científicos, ele tem por necessidade, além do desenvolvimento cognitivo, um desenvolvimento físico, biológico, cultural, social e político, que lhe dê possibilidades de atuar em sociedade com criticidade e autonomia. Gadotti ressalta que:

A educação integral é uma concepção da educação que não se confunde com o horário integral, o tempo integral ou a jornada integral. Alguns projetos de escola de tempo integral surgiram, como é o caso dos Cieps para compensar deficiências do meio familiar, da própria sociedade (GADOTTI, 2009, p.2930).

Nesse sentido, desenvolver a proposta de uma educação integral nada tem a ver com o tempo que se permanece na instituição escolar. Esta educação deveria ser um projeto universal de todas as escolas, um pensamento comum que devido a sua amplitude e complexas açóes deveria atravessar as instâncias responsáveis pela educação. Assim, o tempo integral justifica-se como uma oportunidade para que os alunos possam desenvolver suas atividades escolares com mais tempo e tenham oportunidade de aulas complementares, que em tempo parcial se tornam inviáveis dada sua carga horária já estabelecida pelo currículo escolar (música, dança, artesanato etc.). Entretanto, esse tempo ampliado na escola deve ser pensado, compreendido e planejado segundo objetivos específicos de cada comunidade escolar.

O tempo integral, para ser efetivo, deve ser opção voluntária da escola ou de um conjunto de escolas. Não pode ser imposto. As escolas precisam ter condiçóes para implantar essa inovação educacional. Precisam participar, desde o início, da discussão dessa nova política educacional e acompanhar o seu desenvolvimento. A implantação do tempo integral nas escolas exige preparo técnico- político e formação, tanto dos pais quanto dos alunos, dos professores e demais funcionários da escola (GADOTTI, 2009, p. 36). 
Investir para qualificar é necessário, além de se conhecer os sujeitos e a comunidade que faráo parte desse projeto de educação e ainda contar com um grupo de profissionais que acreditem nessa proposta. Desta forma é possível construir de modo coletivo um projeto de educação que considere o sujeito em sua integralidade e para o ensino da vida. Uma Proposta Político-Pedagógica embasada pela ética e as reais necessidades de uma comunidade é um passo importante para definir com coerência e responsabilidades a educaçáo que se pretende construir.

Enfim, o que se propóe à educação integral é a integralidade, isto é, um princípio pedagógico onde o ensino da língua portuguesa e da matemática não está separado da educação emocional e da formação para a cidadania. $\mathrm{Na}$ educação integral, a aprendizagem é vista sob uma perspectiva holística (GADOTTI, 2009, p.41, 42).

A idealização por uma educação que reconheça o sujeito como humano e que desenvolva suas funçóes emocionais, físicas, cognitivas e sociais tem sido considerada por muitos estudiosos da educaçáo e pelo próprio Estado como a grande saída para a qualificação do sistema educacional brasileiro. Entretanto, há que se pensar em açôes práticas que justifiquem a escolha por este projeto de educação e em meios avaliativos que respeitem os objetivos e intençóes do mesmo.

[...] a educação deveria mostrar e ilustrar o Destino multifacetado do humano: o destino da espécie humana, o destino individual, o destino social, o destino histórico, todos entrelaçados e inseparáveis. Assim, uma das vocaçóes essenciais da educação do futuro será o exame e o estudo da complexidade humana. Conduziria à tomada de conhecimento, por conseguinte, de consciência, da condição comum a todos os humanos e da muito rica e necessária diversidade dos indivíduos, dos povos, das culturas, sobre nosso enraizamento como cidadãos da Terra (MORIN, 2006, p. 61).

Os problemas relacionados à esfera da educaçáo estão longe de serem solucionados, pois implicam decisóes que independem de açôes isoladas e desconexas entre escola, professores e família. Elas envolvem políticas públicas, sociais e econômicas que determinam o lugar e o papel que cada um dos sujeitos e as instituiçóes envolvidas nessa esfera devem cumprir. Contudo, uma reforma do pensamento educacional por parte das instituições responsáveis pela educação e dos professores que nela atuam se faz imprescindível para que possamos construir açóes pedagógicas fortalecidas pela ética, solidariedade e cuidado, rumo à humanizaçáo das relações entre sujeitos.

\section{A reforma do pensamento rumo a um novo modelo de educaçáo escolar}

O paradigma cartesiano é responsável por inaugurar uma nova forma de pensar e produzir conhecimento. Este paradigma tem por base uma única racionalização cognitiva instrumental, que também podemos chamar de racionalidade técnica. Para Descartes o uso da razão poderia levar o homem a descobrir verdades absolutas na natureza e para esse conhecimento era preciso que o objeto em estudo fosse analisado em partes para sua compreensão. Assim, o conhecimento científico no 
paradigma cartesiano precisa compreender que a natureza tem uma ordem e que suas estruturas para serem compreendidas devem ser fragmentadas, simplificadas, para que se conheça.

As raízes do paradigma cartesiano ainda são muito vivas no sistema educacional. A ideia da simplificação e da análise das partes é o método mais utilizado nas práticas curriculares na maioria das escolas. O desenho curricular que se propóe é fragmentado por disciplinas e conteúdos programáticos que engessam a ação pedagógica do professor em sala de aula, limitando a aprendizagem no estudo de partes e náo de um todo contextualizado com o mundo que se vive. Assim aprendemos e assim temos perpetuado a educaçáo para as futuras geraçóes. Entretanto, as mudanças produzidas na sociedade como um todo - políticas, sociais, econômicas e tecnológicas - nos levam a repensar em quais fundamentos nossa educação está pautada e o que objetivamos ao pensar e propor uma reforma na maneira de ensinar e produzir conhecimento na instituiçáo escolar.

Desta forma, não há mais como aceitar o modelo tradicional de ensino que ainda está sendo veiculado nas escolas. Trabalhar somente com certezas no contexto escolar não é possível, precisamos propor uma reforma no pensamento da educação para que possamos nos afastar da fragmentação, do certo ou errado, da simplificação, e avançar na visáo de um todo, da multiplicidade e da pluralidade.

A teoria da complexidade expressa por Edgar Morin nos lembra da importância de nos afastar de uma razão produzida pela modernidade que é simplificadora, reducionista do conhecimento. Segundo Morin:

[...] a viagem em busca de um modo de pensamento capaz de respeitar a multidimensionalidade, a riqueza, o mistério do real, e saber que as determinaçôes-cerebral, cultural, social, histórica-que se impóem a todo o pensamento co-determinam sempre o objeto do conhecimento. É isto que eu designo por pensamento complexo (MORIN, 2008, p. 300).

A educação, nessa perspectiva, tem por objetivo romper essa visão simplificada da realidade, mostrando as correlaçóes que existem entre os saberes, a complexidade da vida e dos problemas da sociedade como um todo. Este deve ser o objetivo da escola, do contrário ela torna-se ineficiente na sua funçáo de educar as futuras geraçóes. Para Morin (2004, p.89), "é preciso substituir um pensamento que isola e separa por um pensamento que distingue e une".

Pensar um novo projeto de educação, que possa olhar para o sujeito em sua individualidade e na sua pluralidade se faz imprescindível. A escola tem sido convocada a repensar sua prática e seu modo de ensinar para que possa conduzir o aluno a entender o universo que vive sem que este separe o global do local, ordem, desordem, razão, emoção. Para Morin, o maior problema para a reforma do pensamento, é que os sujeitos aprenderam a separar, a dividir, a se fixar numa inteligência que é cega, porque não enxerga os objetos dentro do conjunto de sua totalidade (MORIN, 2003). Assim sendo, esse autor reforça a necessidade de mudança no pensamento da educação, numa lógica que supere a simplificação do conhecimento. Desta forma: 
O pensamento complexo estabelece um canal de diálogo entre os diferentes paradigmas: entre o homem e as ideias que ele produz; entre o ser humano e suas racionalizaçóes, enfim, entre os diferentes saberes e ciências. No pensar complexo integram-se pontos de vista diferentes, às vezes, antagônicos, concorrentes ou complementares, incluindo os mais diversos campos da racionalidade humana, seja ela mítica, religiosa ou científica (MARTINAZZO; CHEROBINI, 2005, p. 66,).

A complexidade nos ajuda a integrar aquilo que está separado, isolado produzindo um elo de recursividade que nos projeta para pensar complexo, sem esquecer a importância das partes e do todo no percurso do conhecimento escolar.

A proposta de Educação Integral vem com o intuito de perceber a imprescindibilidade de um currículo escolar que conceba o sujeito em suas múltiplas dimensões (social, ética, política, estética etc.), e que através das açôes pedagógicas possa responder aos desafios da sociedade contemporânea e das diferentes situaçóes que se apresentam a todo o instante e merecem análise profunda e náo superficial. De acordo com Morin (2003, p.100), "não se pode reformar a instituição sem uma prévia reforma das mentes, mas náo se podem reformar as mentes sem uma previa reforma das instituiçôes".

Superar a compreensão do currículo escolar enquanto artefato técnico burocrático, fragmentado, autoritário e disciplinador também é um desafio para compreendermos a importância do pensamento complexo para a educação. É preciso entender o currículo como produtor de cultura, como um sistema complexo que articula saberes e poderes para que possamos avançar rumo a uma reforma do pensamento da educação e da proposta que se pretende inovadora. Assim sendo,

Faz-se urgente o surgimento de uma ciência sistêmica e complexa que reagrupe e ultrapasse as disciplinas, que considere os problemas do planeta, do ser humano e da vida em geral como um todo complexo. Enquanto o pensamento científico promove a hiperespecialização com base num saber parcelar, redutor, disjuntor, detalhista e isolante, o bom e sadio pensamento é sempre conectante e consegue integrar as dimensóes do conhecimento complexo que são intercomplementares e, ao mesmo tempo, concorrentes e antagônicas (MARTINAZZO; CHEROBINI, 2005, p. 61).

Ciência esta que possibilite o diálogo, a contextualização dos diferentes saberes e áreas do conhecimento numa perspectiva humana e emancipatória do sujeito nela envolvido. Que a prática pedagógica do professor seja alicerçada nessa Ciência, que religa saberes, que respeita, que incentiva e que promove aprendizagens. A proposta por uma educação integral objetiva olha o sujeito na sua integralidade e desenvolve suas habilidades considerando o todo do sujeito e náo apenas seu intelecto. Esta proposta requer uma reforma curricular e paradigmática no intuito de romper com a fragmentação e superar as fragilidades que assolam a educaçáo escolar no entendimento de uma perspectiva educacional que forme sujeitos para viverem com ética e responsabilidade no mundo em que se vive. 


\section{Consideraçóes finais}

Nós, humanos, vivemos em uma sociedade complexa, atravessada pela tecnologia e pela informação, que nos exige pensar e nos ressignificar a todo o momento para que possamos acompanhar a velocidade das mudanças que nos cercam. Essas mudanças reforçam a certeza de que é necessário construir uma visão de mundo ampla, que ultrapasse a ideia da fragmentação das partes, tornando o conhecimento técnico e alienado em si. O paradigma cartesiano nos ensinou a aprender dessa forma, sem que os sujeitos pudessem compreender a totalidade das coisas do mundo. Esse modo de ensinar perdura na maioria das instituiçóes escolares, que se vê paralisada com tantas demandas da sociedade e náo encontra saída para inovar sua prática pedagógica e ultrapassar as fronteiras históricas das disciplinas escolares.

Apostar na educação como forma de emancipar o sujeito na perspectiva de construir uma sociedade mais humana e mais justa foi, sem dúvida, o eixo motor do caminho investigativo traçado na consciência de ser esta a finalidade social da escola. Um país que investe em educação e em políticas públicas que assegurem os direitos dos cidadáos tende a avançar para o desenvolvimento. Desta forma, a proposta de uma educação integral no currículo escolar traz a possibilidade de desenvolver práticas pedagógicas com vistas para a religaçáo de saberes embasado por um trabalho interdisciplinar que vise formação humana e social do sujeito e sua interação com o mundo em que vive.

\section{Referências}

GADOTTI, Moacir. Educaçáo integral no Brasil: inovaçóes em processo. São Paulo: Editora e Livraria Instituto Paulo Freire, 2009.

GUARÁ, Isa Maria F. Rosa. É imprescindível Educar Integralmente. Cadernos Cenpec, n. 2, p. $15-24,2006$.

MARTINAZZO, Celso J.; CHEROBINI, Ana L. Pedagogia e Complexidade: implicaçóes e transdisciplinaridade. Revista Contexto e Educaçáo, Editora Unijuí, ano 20, no 73/74, p.55-72, Jan/Dez, 2005.

MOLL, Jaqueline. Conceitos e Pressupostos: O que queremos dizer quando falamos de Educação Integral? In: Educaçáo Integral: Salto para o futuro, ano XVIII, boletim 13, p.11- 16, 2008.

MORIN, Edgar. Ciência com Consciência. Rio de Janeiro: Bertand Brasil, 2008.

MORIN, Edgar. Os sete saberes necessários à educaçáo do futuro. Tradução de Catarina Eleonora F. da Silva e Jeanne Sawaya. Revisão técnica de Edgard de Assis Carvalho. 11 ed. São Paulo: Cortez; Brasília, DF: UNESCO, 2006.

MORIN, Edgar. Educaçáo e complexidade: os sete saberes e outros ensaios. São Paulo: Cortez, 2004. 
MORIN, Edgar. A cabeça bem-feita: repensar a reforma e reformar o pensamento. Rio de Janeiro: Bertrand Brasil, 2003.

ROTHER, Edna Terezinha. Revisão sistemática X revisão narrativa. Acta paul. enferm., São Paulo, v. 20, n. 2, p. 5-6, 2007. 